\title{
Scamper Technique to promote creative thinking and learning the compound attack in fencing Dr/ Mona Mohamed-Kamal Hijazi*
}

Creativity is an effective mean of reducing the cultural and scientific gap between nations. It is also a crucial factor in the progress of societies in all areas of human activity. There are many types of thinking, one of the most important is creative thinking. Revealing the creative thinking skills is very important, as possessing these skills has a positive impact on the entire educational process. The importance of this research in being one of the studies that is concerned about involvement of students in the learning process by using an unconventional technique, which may contribute to increasing their learning of offensive skills and developing the level of creative thinking. This study aimed to identify the effect of using SCAMPER on the creative thinking and the level of compound attack in fencing among female students. The researcher used the experimental method by using pre and post measurements for creative thinking level by using The Figural TTCT "Torrance Tests of Creative Thinking", and the post-measurement for compound attack, using two groups, experimental and control, on a sample of (51) second year female students on the Faculty of Physical Education, Sadat City University, (11) for survey study, (40) for basic study. The results showed that the level of creative thinking of the study sample was low. There were statistically significant differences between pre and post measurements for the experimental group in each of creative thinking abilities (originality, flexibility, detail perception, fluency), and the total sum of creative thinking in the direction of postmeasurements. While for the control group there were statistically significant differences between pre and post measurements in flexibility only and statistically insignificant in each of creative thinking abilities (originality, detail perception, fluency), and the total Assiut Journal For Sport Science Arts 
sum of creative thinking. There were statistically significant differences in the post-measurements between the experimental and the control groups at the level of each of the abilities (originality, flexibility, detail perception, fluency) and the total sum of creative thinking, in the direction of experimental group.

Key words: SCAMPER Technique, creative thinking, compound attack, fencing.

\section{Introduction:}

"Creative do not Imitate" A slogan adopted by many developed countries, a slogan that must be adopted by the entire Arab countries, peoples and governments.

Creativity is an effective means of reducing the cultural and scientific gap between nations. It is also a crucial factor in the progress of societies in all areas of human activity (Kanani, M., 2005: 15).

Thinking of the sophisticated psychological operations through which we can access to abstract levels and more complex meanings of things, events and the relationships between these things and events In order to overcome the difficulties that we face (Ramzi, T., 1996: 161). It is also a resource to provide individuals with a set of strategies through which they can better interact with their environment (Abdel Hadi, N., Abu Hashish, A., Basendi, K., A., 2009: 51).

Thinking is a mental activity of the individual in order to obtain permanent or temporary solutions of a problem. It is one of the highest mental and psychological processes that distinguish humans from other organisms (Mustafa, F., 2002: 27). It represents the most complex forms of human behavior and comes at the Assiut Journal For Sport Science Arts 
highest level of mental activity and is the product of the brain with all its complexity (Abdul Aziz, S., 2009: 21).

Scientists point out that there are many types of thinking, namely: reasoning, visual, critical, meditative, systemic and creative thinking (Obaid, W.,Afana,E.,2003: 41).

Revealing the creative thinking skills is very important, as possessing these skills has a positive impact on the entire educational process, and creative thinking is not human instinct, his skills are educated and derived from the environment, and can be learned as any other skill, but it requires regular and continuous training, starting with basic thinking skills and gradually increasing to higher thinking processes.

Studies have shown weaknesses in higher thinking processes, which have led to a recent increase in interest in improving and developing higher thinking skills for students at all study stages.

Educators must ensure that the ultimate objective of education being in the development of learners' thinking skills. Teaching staff in different fields should have structured experiences to help them understand, analyze, and develop their thinking processes.

(Slabbert, 1994: 64), pointed out that a teacher is handicapped for creativity in teaching when he is not convinced of the process of creativity and its importance as an educational goal, when he is not ready to meet the needs of the learners, and then does not know how to start or evaluate creative abilities.

However (Française, 2004: 2), suggested that the creative teacher is that who uses a different education strategies related to the 
development of creative thinking.

Creative thinking provides the community with the ideas that it lacks and which it aspires to, this in order to transfer from traditional to contemporary and modernization. Modern educational trends have gone to focus on learning through inquiry, discovery and thinking, And reducing indoctrination and direct education.

As educational institutions ignore the attention and development of mental processes, this made the students take a rigid mold in their thinking which is moving with them from one level of study to another, making them resort to traditional solutions to problems free from creativity and innovation, which made scientists and thinkers resort to the creation of methods that can contribute to provide young people with nontraditional intellectual skills in a scientific and direct manner, and of these methods, develop thinking education programs, (Waly, M., Al-Obeidi, B., AlObeidi, O., (2010 : 12).

There are many thinking education programs and skills such as "Gilford's Mental Construction Program", aiming to develop the cognitive skills of thinking such as "conclusion, classification and comparison", and the "Courtbono" program, (a learningdiscovery program) that aims to provide learners with several strategies to solve problems (Jarwan, 2016: 75).

From the strategies of developing creative thinking is Scamper's list (one of the modern strategies) to develop thinking, stimulates imagination to innovate, and create new ways of dealing with various life situations, 
including problem solving in an innovative way.

The creator of "Scamper" is "Eberle, B" whose idea is to develop and improve ideas and come up with a new idea, through a series of steps to change the product data and reconfigure or shape the relationship. Scamper's strategy helps solve problems creatively and generate new ideas.

The word "SCAMPER" means idiomatically "run with quick light steps, especially through fear or excitement",
SCAMPER is an activity based thinking process that can be performed by Cooperative learning. Here the teacher assists the students in choosing a particular topic and helps them to develop it through a structured process. After choosing an idea, the students are given a tale where they perform the activity in steps corresponding to the letters in the name, which in its entirety constitute the "List Generating Ideas", which is illustrated in the following figure.

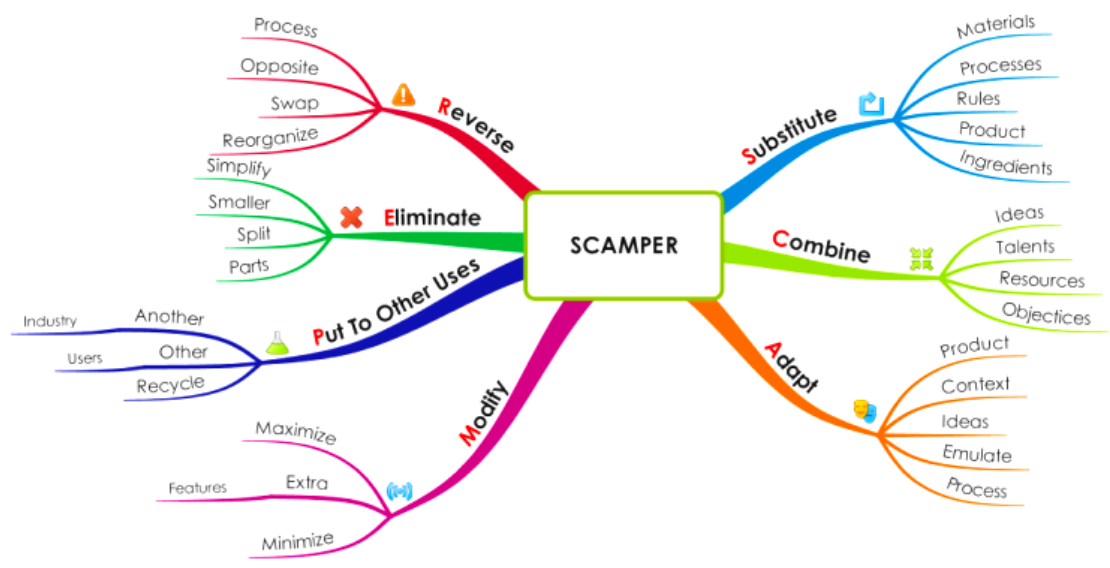

Figure (1)

List Generating Ideas

Assiut Journal For Sport Science Arts 
Fencing is an individual sport based on mind and good thinking, a sport of mind and body. Fencing in particular is a very mental sport. In fact, the mental part of the game is just as important, if not more critical, when it's time to compete. Getting good as a fencer in practice is $95 \%$ physical and 5\% mental. However, once you face off against your opponent, the percentages flip flop. Being successful is $95 \%$ mental and $5 \%$ physical.

The importance of this research in being one of the studies that concerned about involvement of students in the learning process by using an unconventional strategy, which may contribute to increasing their learning of offensive skills and developing the level of creative thinking which is considered the finest type of human thinking which leads to progress. The researcher noted the low level of thinking among students in different stages of study, which is clear from the results of studies and research conducted in this area, because the curricula at different stages of education does not develop thinking and creativity, and that creativity is a mental ability deposited by God in the human, and can be developed by training, which prompted the researcher to choose a new program that believes it has a great effectiveness in the development of creative thinking among students, And within the knowledge of the researcher has never been used to develop creative thinking in sports field.

\section{Aim of the study:}

This study aimed to identify the effect of using SCAMPER on the creative thinking and the level of compound attack in fencing among female students. 
Hypotheses of the study:

- There are significant differences between the averages of pre and post measurements for experimental and control groups in creative thinking level.

- There are significant differences between the experimental and control groups in the post measurements in the level of both creative thinking and compound attack.

Materials and Methods Data collection

- The Figural TTCT: Thinking Creatively with Pictures "form b". This test measures four dimensions of creative thinking (originality, flexibility, detail perception, fluency), the test consists of three sub-activities: "Picture Construction Activity", "Incomplete Figure Activity", "Repeated Figure Activity", each takes ten minutes so that the total time with instruction reading is 45 minutes.

\section{Study method}

The researcher used the experimental method by using pre and post measurements for creative thinking level and the post-measurement for compound attack, using two groups, experimental and control.

\section{Participant :}

Participants were 51 second year female students on the Faculty of Physical Education, Sadat City University for the academic year 2015/2016, (11) for survey study, (40) for basic study were divided into two groups, one experimental and the other is control, the strength of each group 20 female students, SCAMPER tools have been applied to the experimental group, the conventional method has been applied to the control group. 
The skewness coefficient of the research variables confined between \pm 3 which indicates moderating of distribution, and there are no significant differences between experimental and control groups in the pre measurements which indicates equality of the two groups in the research variables.

\section{Research procedures:}

\section{Survey study}

The researcher conducted the survey study on a sample of 11 female students from the same research community and outside the research participants in the period from February 21, to February 23, 2016, and for the purpose of rationing scientific coefficients for research tools.

Scientific coefficients for tests:

\section{First: validity}

For creative thinking test the researcher calculated the validity of internal consistency of the creative thinking test, which included (4) abilities in order to find the correlation coefficient between the degree of each ability and the total score of the test, and was reached that there is a statistically significant correlation between the score of each ability and the total score of the test.

\section{Second: reliability}

For creative thinking test, the researcher calculates the test stability by Cronbach's alpha coefficient of the responses of the survey sample of (11) female students, and the stability of the value of alpha coefficient was 0.760 . Which demonstrates that the test of creative thinking has a high degree of stability.

2. Pre- measurements:

Pre- measurements were conducted for the basic research sample on March 1, to March 2, 2016, they included 
measuring the level of creative thinking of female students.

3. Implementation of the program:

The SCAMPER's tools were implemented in the period from March 9, to April 27,
2016 , at a rate of two hours per week, and lasted for (8) weeks.

4. Post measurements:

Post measurements were conducted in May 3, to May 4, 2016.

Results

Table (1)

Significant differences between pre and post measurements for the experimental group in creative thinking

\begin{tabular}{cccccc}
\hline \hline \multirow{2}{*}{ Ability } & \multicolumn{2}{c}{ Pre test } & \multicolumn{2}{c}{ Post test } & \\
\cline { 2 - 5 } & Mean & $\begin{array}{c}\text { Std. } \\
\text { Deviation }\end{array}$ & Mean & $\begin{array}{c}\text { Std. } \\
\text { Deviation }\end{array}$ & t \\
\hline \hline originality & 19.65 & 3.815 & 22.35 & 3.265 & $8.301^{*}$ \\
\hline flexibility & 10.85 & 2.368 & 12.70 & 2.638 & $7.955^{*}$ \\
\hline $\begin{array}{c}\text { detail } \\
\text { perception }\end{array}$ & 45.15 & 12.171 & 54.30 & 12.066 & $5.656^{*}$ \\
\hline fluency & 9.25 & 1.650 & 10.95 & 1.701 & $10.376^{*}$ \\
\hline total & 84.90 & 14.082 & 100.30 & 12.803 & $9.131^{*}$ \\
\hline \hline
\end{tabular}

$\mathrm{T}$ Table value for df 19 and the level of $0.05=2.093$

It is seen from the table that there are statistically significant differences between pre and post measurements for the experimental group in each of creative thinking abilities (originality, flexibility, detail perception, fluency), and the total sum of creative thinking. 
Table (2)

Significant differences between pre and post measurements for the control group in creative thinking

\begin{tabular}{cccccc}
\hline \hline \multirow{2}{*}{ Ability } & \multicolumn{2}{c}{ Pre test } & \multicolumn{2}{c}{ Post test } & \\
\cline { 2 - 5 } & Mean & $\begin{array}{c}\text { Std. } \\
\text { Deviation }\end{array}$ & Mean & $\begin{array}{c}\text { Std. } \\
\text { Deviation }\end{array}$ & $\mathbf{t}$ \\
\hline \hline originality & 20.15 & 4.344 & 19.70 & 4.485 & 1.000 \\
\hline flexibility & 10.45 & 2.373 & 10.95 & 2.139 & $2.236^{*}$ \\
\hline $\begin{array}{c}\text { detail } \\
\text { perception }\end{array}$ & 45.80 & 10.890 & 46.45 & 11.528 & .928 \\
\hline fluency & 8.35 & 1.424 & 8.45 & 1.669 & .623 \\
\hline total & 84.75 & 11.607 & 85.55 & 11.945 & .837 \\
\hline \hline
\end{tabular}

T Table value for df 19 and the level of $0.05=2.093$

It is seen from the table that there are statistically significant differences between pre and post measurements for the control group in flexibility only and non-statistically

\section{Table (3)}

Significant differences between the experimental and control groups in the post measurement in creative thinking

\begin{tabular}{|c|c|c|c|c|c|}
\hline & \multicolumn{2}{|c|}{$\begin{array}{c}\text { The experimental } \\
\text { group }\end{array}$} & \multicolumn{2}{|c|}{ The control group } & \multirow[b]{2}{*}{$\mathbf{t}$} \\
\hline & Mean & $\begin{array}{c}\text { Std. } \\
\text { Deviation }\end{array}$ & Mean & $\begin{array}{c}\text { Std. } \\
\text { Deviation }\end{array}$ & \\
\hline originality & 22.35 & 3.265 & 19.70 & 4.485 & $2.136^{*}$ \\
\hline flexibility & 12.70 & 2.638 & 10.95 & 2.139 & $2.304 *$ \\
\hline $\begin{array}{c}\text { detail } \\
\text { perception }\end{array}$ & 54.30 & 12.066 & 46.45 & 11.528 & $2.104 *$ \\
\hline fluency & 10.95 & 1.701 & 8.45 & 1.669 & $4.692 *$ \\
\hline total & 100.30 & 12.803 & 85.55 & 11.945 & $3.767^{*}$ \\
\hline $\begin{array}{l}\text { Compound } \\
\text { attack }\end{array}$ & 14.85 & 2.033 & 13.25 & 1.713 & $2.691^{*}$ \\
\hline
\end{tabular}

T Table value for df 38 and the level of $0.05=2.042$

Assiut Journal For Sport Science Arts 
It is seen from the table that there are a statistically significant differences in the post measurement between the experimental and control group in in each of creative thinking abilities (originality, flexibility, detail perception, fluency), and the total sum of creative thinking and the level of compound attack.

\section{Discussion}

The results showed that the level of creative thinking of the study sample is low, where the average score on the Torrance scale of creative thinking "form $b$ " for the pre measurement was "84.83". This is because teaching methods at different educational stages do not care to develop thinking skills, especially creative thinking, whereas Creative thinking is a mental ability that can be developed by training. (Glenn, 1997: 67) notes that educational systems in general, and despite the results of research and studies that emphasize the importance of promoting creativity and motivation among students, but it really does not help that.

In his study, (Nabhan, 2001: 2) noted that many educators have realized in recent years that students in schools do not think as skillfully as they should. A number of recent articles, research and studies have shown weaknesses in higher thinking processes.

The results of tables (1) and (2) showed that there are statistically significant differences between pre and post measurements for the experimental group in each of creative thinking abilities (originality, flexibility, detail perception, fluency), and the total sum of creative thinking. While for the control group there are statistically significant differences between pre and post measurements in flexibility only and nonstatistically significant in each of creative thinking abilities Assiut Journal For Sport Science Arts 
(originality, detail perception, fluency), and the total sum of creative thinking.

The rates of change between pre and postmeasurements in each of creative thinking abilities (originality, flexibility, detail perception, fluency), and the total sum of creative thinking of the experimental group ranged from $13.74 \%$ to $20.27 \%$. While in the control group it ranged from $1.20 \%$ to $4.78 \%$.

This demonstrates the positive impact of using SCAMPER technique on the level of creative thinking among students, (Al-Jamal, 2005: 43) indicate that higher thinking skills and processes do not grow automatically for students by learning subjects in traditional methods, But perhaps these methods may hinder the growth of higher thinking abilities, and it also works to limit these abilities to their limits and minimum levels.

As shown in Table (2) the average degree of originality in the postmeasurement was lower than in the pre-measurement for the control group, where the degree of originality indicates the ability of the examinee to produce new and non-repetitive responses within the group to which he belongs, (Khairallah, 1981: 13) explains that the degree of originality is measured by the ability of the examinee to mention answers are not common in the group to which he belongs, The less the statistical repetition of any idea the greater the degree of authenticity and vice versa, In the sense that the greater the statistical repetition of the idea, the lower the degree of originality of the individual.

The results of Table (3) showed that there were statistically significant 
differences in the postmeasurements between the experimental and the control groups at the level of each of the abilities (originality, flexibility, detail perception, fluency) and the total of creative thinking, in the direction of experimental group. This illustrates the impact of using SCAMPER technique on the level of creative thinking, Whereas, Cognitive and affective processes, contained in SCAMPER technique Encourage thinking in a way that has not been commonplace before, Allows to acquire different thinking skills, Encourages discovery, it also helps in flexibility and break the stereotypes in thinking. And he has pointed out (Serrat, 2009: 2) that SCAMPER technique used to solve problems, where the learner must identify the problem to be solved, or the idea to be developed, or the product we want to improve, And, therefore, to rely on SCAMPER 's questions that stimulate ideas, This would develop higher thinking skills, especially creative thinking.

The results of Table (3) showed that there are statistically significant differences in postmeasurements between the experimental and control groups, in the direction of the experimental group at the level of compound attack, Where SCAMPER technique helps students to generate new or alternative ideas, As well as training them in the imagination, and conducting mental processes, through List Generating Ideas, This contributes to development of creative thinking, and also helps students to be active and positive, And through some steps deduced knowledge 
himself and learning based on the understanding happens.

This is confirmed by (Eberle, 2008: 4), (Gladding \& Henderson, 2000: 248) that the advantages of using SCAMPER technique in learning are to Activating the role of learners in educational situations, motivate them to generate ideas, And develop thinking skills, especially the creative thinking of learners. It also helps to form positive attitudes among students towards learning course material, where the environment that develops creativity is characterized by an encouraging climate for the new, Accepts non-conventional solutions, Develop selflearning methods, In addition to blocking criticism of new ideas And acceptance of difference and excellence.

(Torrance, 1997: 71) emphasized that future schools should be designed not only for education but also for thinking. And focuses on that the original creativity requires a lot of performance, perfection, and difficulty, it can make learning fun, exciting, challenging, but it cannot make it easy. (Eisner, 1990: 424) claimed that one of the real goals of the school in the nineties was to teach students that the introduction of ideas, interesting and exciting, raise the interest of students in the learning process, And give them experiences of interaction and work with the real problems. "Piaget" saw that the main goal of education is to graduate individuals who are able to do new things and not repeat what previous generations did, so that they are able to innovate and to detect new (Lakani, 1995: 64).

\section{Conclusions}

Based on results of this study, the following conclusions can be drawn: 
- The level of creative thinking is low among students.

- The use of the SCAMPER technique with female students positively affects the level of creative thinking.

- The use of the SCAMPER technique with female students positively affects the level of learning the compound attack.

\section{Practical Implications}

Based on the aim of the study and the collected data, the following implications can be made:

- The need to focus in education on the use of methods that develop thinking and not just information.

- Using the SCAMPER technique in education in different educational stages (schools and universities).

- The use of teaching methods and other programs to learn thinking, especially creative thinking in different stages of education, especially in the first stages of education.

\section{References}

\section{1- Abdel Hadi, N., Abu} Hashish, A., Basendi, K., A. (2009): Skills in Language and Thinking, (3rd ed.), Dar AlMasirah, Amman.

2- Abdul Aziz, S. (2009): Teaching Thinking and Skills "Practical Training and Applications", Dar Al-Thaqafa Publishing and Distribution, (2nd ed.), Amman.

3- Al-Jamal, M. (2005): Developing creative thinking skills through the curriculum, Dar Al-Ketab Al-Jami, AlAin.

4- Al-Laqani, A. (1995): Curriculum (foundations, components, regulations), Dar Alam Al-kotob, Riyadh.

5- Francis, T., M. (2004): Art and Methods of Teaching, Dar Al-Farouk Publishing and Distribution, Cairo. 
6- Jarwan, F. (2016): Teaching Thinking Concepts and Applications, (9th ed.), Dar Al-Fikr for Printing, Publishing and Distribution, Amman.

7- Kanani, M. (2005): The Psychology of Creativity and its Methods of Development, Dar Al-Masirah, Amman.

8- Khairallah, S., M. (1981): Testing the ability to think creatively, Alam Al-Ketab, Cairo.

9- Mustafa, F. (2002): Thinking Skills in the General Education Stage

"KindergartensPrimaryPreparatorySecondary" Future Vision for Education in the Arab World, Dar Al-Fikr Al-Arabi, Cairo.

10- Obaid, W., Afana, E. (2003): Thinking and Curriculum, Al-Falah Library for Publishing and Distribution, Al-Ain.

11- Ramzi, T. (1996): Introduction to Psychology, (2nd ed.), Dar Al-fekr Almoaser, Beirut.

12- Eberle, B.(2008). SCAMPER: Creative games and activities for imagination development (2nd ed.), TX: Prufrack Press.

ISBN 1593633467

\section{3- Elliot W. Eisner (1990):}

Discipline-Based

Art

Education: Conceptions and Misconceptions, Educational Theory, Fall 1990, Vol. 40, Issue 4, pp 423 - 430.

14- Gladding, S. \& Henderson, D. (2000). Creativity and family counseling: The SCAMPER model as a template for promoting creative processes. The Family Journal, Vol. 8, Issue 3, pp.245-249

15- Glenn, R.E. (1997), "SCAMPER for Student Creativity", Education Digest, Vol. 62 Issue 6, pp67-69.

16- Nabhan, S. (2001): A proposed program for the development of critical 
thinking in mathematics for ninth grade students in Gaza Governorate, unpublished doctoral thesis, Faculty of Education, Ain Shams University.

17- Serrat, O. (2009): The SCAMPER Technique. International Publications, Cornell University ILR School. Available form :

18- Slabbert, J. A. (1994). Creativity in education revisited: Reflection in aid of progression. The Journal of Creative Behavior, Vol. 28, Issue 1, pp 60 - 69 .
19- Torrance, E.P. (1997).The nature of creativity as manifest in its testing .In Sternberg, R.J. (Ed.) The Nature of Creativity Cambridge, UK: Cambridge University Press, pp.43- 75. 20- http://digitalcommons.ilr. cornell.edu/intl/192.[Accessed: 5 May 2016]. 21- Waly, M., Al-Obeidi, B., Al-Obeidi, O., (2010): Creativity, Innovative Thinking and Development in Education, Dibono for Printing, Publishing and Distribution, Amman. 